\title{
Statistical Analysis of Factors Affecting Average Monthly Saving Money of Lecturers in Case of Natural and Computational Science
}

\author{
Sewale Million Dagnachew, Assaye Belay Gelaw \\ Department of Statistics, Mizan-Tepi University, Tepi, Ethiopia \\ Email address: \\ SewaleMillion21@gmail.com (S. M. Dagnachew), abstat23@gmail.com (A. B. Gelaw)

\section{To cite this article:} \\ Sewale Million Dagnachew, Assaye Belay Gelaw. Statistical Analysis of Factors Affecting Average Monthly Saving Money of Lecturers in \\ Case of Natural and Computational Science. Science Journal of Applied Mathematics and Statistics. Vol. 7, No. 5, 2019, pp. 83-88. \\ doi: 10.11648/j.sjams.20190705.14
}

Received: May 16, 2019; Accepted: October 21, 2019; Published: October 25, 2019

\begin{abstract}
This study entitled by determinants of average money saving in university lecturers in case of Mizan-Tepi University Tepi Campus in the College of Natural and Computational Science. The amount of saving is influenced by different factors: monthly income, family size, and age and family consumption per capital. The objective of the study was to examine the responsible factors on average saving monthly income of lecturer's in Mizan- Tepi University, Tepi Campus. The study included about 135 teachers (lecturers). The data for the research was collected from primary source and structural questionnaires were administered. The dependent variable was average saving monthly income and the independent variables are factors like; family consumption per month, family size, recreation, age, marital status, religion, donation, and house rent, sex, and work experience. From multiple linear regressions analysis on the effect of average monthly income of lecturers was family consumption, family size, and age. The data were analyzed using SAS version 9.2 and finding also compared with relevant literatures, lastly conclusions drawn and recommendation was for warded from the result. It was concluded that from 135 teachers (lecturers), $86.79 \%$ of the teachers (lecturers) are male and $13.21 \%$ are females who saved money prevalently and age, net salary, family size and consumption per month were significantly influencing on average saving money of lecturers' in case of Natural and Computational science.
\end{abstract}

Keywords: Income, Multiple Linear Regression, Saving

\section{Introduction}

Personal saving has two primary functions. First, savings provide the economic security of a safety net. By transferring resources from the present to the future via savings, individuals are prepares to face unexpected and irregular financial circumstances. Second, saving leads to accumulation of wealth that enables individuals to improve their living standard and to response to new opportunities [1].

People used traditional money saving system because modern money saving system was not improved at that time [2] Statistics for Business and Economics: $8^{\text {th }}$ edition). When it comes to saving, people in general and the poor in particular might not be completely rational and completely knowledgeable [3]. The goal of promoting financial saving habit is to make people more aware of financial opportunities, choices, and possible consequences. There is a growing recognition of the importance of financial education as it relates to saving [4]. Naturally, some have turned towards the high yield saving accounts of on time banks. They could save money throughout the year, but watch Temperatures of summer provided a few additional tips that could help they saved ever more money [5].

The methods of saving include putting money aside in bank or pension plan and include reduced expenditure. Saving is closely related with investment. It is possible for resource to be invested by being used to produce fixed capital variable like factories and machinery. It can therefore be vital to increase the amount of fixed capital variable, which contribute to economic growth. However, increase saving do not always corresponding to increase investment [6]. Basic concepts of Education and curriculum: Financial education is one way of increasing savings and asset accumulation. The 
extent to which an individual understands the process and benefits of asset accumulation is likely to affect their willingness to save. Thus, Mizan-Tepi University was selected for present study [7]. Saving money is a deposit account paying interest is typically used to hold money for future need. In case there was some disagreement about Money saving. For example, one part of people (teachers) income that was spent on mortgage loan repayments it was not spent on increase without increase investment. So, by the above definition even though teachers do not always thought repaying as saving because others said it was hard to save a portion of their income due to extravagance [8] Statistics for Business and Economics.

Saving is a mechanism by which people meet their future need. The basis of saving helps their own Future interest or their family interest or for in parting education to their or for building or as a safe guard against hard shipping during old age sickness. Saving is defined the difference between income and consumption. From the psychological point of view saving can be considered the result of a deliberate decision making process and saving is the act of regularly putting away some resource for a goal [9]. These saving money resources will provide a foundation and answer the question such as "how much money I should saving" and "what is difference between saving and investing?" You will also learn the mobilization of saving was forgotten half of development finance paradigm [10].

\section{Methodology}

\subsection{Study Area and Variables}

The study was conducted in Mizan-Tepi University Tepi Campus in the college of Natural and computational science which located $611 \mathrm{~km}$ east of National capital city Addis Ababa and about $899 \mathrm{~km}$ from the regional capital city of Hawassa. Mizan-Tepi University Tepi Campus was established or started teaching learning activities in 2000 E.c academic year as a University. The establishment of University is alone with government policy and expanding quality higher education and ensuring its equitable distribution across the country.

The target Population considered the factor that affects money saving in lecturers in case of College of Natural and Computational science. Therefore, the study was done in College of Natural and Computational science lecturers. During the practical implementation the samples selected from the target population. The dependent variable is the amount of average money saved by lecturers per month and independent variables are sex, religion, marital status, donation, recreation, family size, family consumption, age, gross salary of lecturers, experience and house rent.

\subsection{Methods of Data Collection}

This information would be collected through self administered questionnaire by preparing questions for the respondents (teachers) to make the study feasible and accurate. The questionnaire had open and closed ended questions.

\subsection{Sampling Technique}

Simple random sampling was used and each member in population has equal chance of being selected. The following measurements were used to determine the sample size: The degree of confidence, the margin of error (the degree of precision) is $95 \%$ and $5 \%$ respectively. From pilot survey, the variance of samples was computed and given by the formula [11]:

$$
\mathrm{n}=\frac{\mathrm{Z}^{2} \alpha / 2}{\mathrm{~d}^{2}} \mathrm{~S}^{2}=135
$$

where $S^{2}$ is the sample variance of average money saving, $\mathrm{Z}$ : statndard normal distribution, $\mathrm{d}$ : marginal error and $\alpha$ : level of signficance.

\subsection{Methods of Data Analysis}

It contained the data collection, organization, summarization and presentation or summary were done in descriptive statistics.

Histogram: It represents the category of the level of education and number of frequencies in each with vertical axis. Generally, descriptive statistics is used to measure the mean, median of amount of money saved per month.

Inferential Statistics: It consisted of organizing from samples to populations performing hypothesis testing determining relationships among variables and making conclusions. In the inferential statistics the method of data analysis contains a regression analysis that is multiple linear regressions.

Multiple Linear Regression Model

It shows the linear function of all regresses with regressed.

$$
\text { Model: } Y=\beta_{0}+\beta_{1} X_{1}+\beta_{2} X_{2}+\beta_{3} X_{3}+\beta_{4} X_{4}+\beta_{5} X_{5}+\beta_{6} X_{6}+\beta_{7} X_{7}+\beta_{8} X_{8}+\beta_{9} X_{9}+\beta_{10} X_{10}+\beta_{11} X_{11}+\varepsilon
$$

Where: $y=$ average money saving (regressed)

$\beta_{0}=$ constant, $\left(\beta_{1} \ldots \beta_{11}\right)=$ parameters of the repressors, $\left(X_{1} \ldots X_{11}\right)=$ Regresses (monthly income, consumption, marital status, religion, sex, house rent, donation, recreation, family size, experience and age) and $\varepsilon=$ Random of disturbance term.

Assumption for Multiple Regressions Model

All statistical procedures and results extracted from such analysis are valid and have meaning only if the standard regression assumptions are satisfied. When these assumptions are violated, the standard results quoted previously do not hold and an application of them may lead to serious error. In addition, gross violations of the assumptions may lead an unstable model in the sense that a different sample could lead to a totally different models with opposite conclusions. Therefore, the regression assumptions 
should be checked before drawing statistical conclusions from the analysis because the validity of these statistical procedures hinges on the validity of the assumptions.

These standard regression assumptions are given as

$$
y_{i}=\beta_{0}+\beta_{1} x_{i 1}+\beta_{2} x_{i 2}+\beta_{3} x_{i 3}+\beta_{4} x_{i 4}+\beta_{5} x_{i 5}+\beta_{6} x_{i 6}+\beta_{7} x_{i 7}+\beta_{8} x_{i 8}+\beta_{9} x_{i 9}+\beta_{10} x_{i 10}+\beta_{11} x_{i 11}+\varepsilon_{i}
$$

Assumption of non-stochastic repressors: The predictor variables are non random (or they are deterministic) and they are measured without error.

Assumption of no multi-co linearity: The predictor variables are linearly independent of each other.

Assumption of zero mean error: The error terms, $\varepsilon_{i}{ }^{\prime} s$ have

$$
\operatorname{Var}\left(\varepsilon_{i}\right)=E\left[\left(\varepsilon_{i}-E\left(\varepsilon_{i}\right)\right]^{2}=E\left(\varepsilon_{i}^{2}\right)=\sigma^{2} \text { for } \forall i=1,2, \cdots, n\right.
$$

Assumption of no autocorrelation: The errors $\varepsilon_{i}{ }^{\prime} s$ are uncorrelated. This is:

$$
\operatorname{Cov}\left(\varepsilon_{i}\right)=E\left[\left(\varepsilon_{i}-E\left(\varepsilon_{i}\right)\right)\left(\varepsilon_{j}-E\left(\varepsilon_{j}\right)\right)\right]=E\left(\varepsilon_{i}^{2}\right)=\sigma^{2} \text { for } \forall i \neq j=1,2, \cdots, n .
$$

Assumption of normality: The errors are normally distributed. Assumptions on the error terms can collectively expressed by:

$$
\varepsilon_{i} \sim N I D\left(0, \sigma^{2}\right)
$$

where NID stands for "Normally and independently

distributed". The model rewrites in matrix form as follows:

$$
Y=X_{\beta}+\varepsilon
$$

The estimation of regression parameters applies by using least square estimation.

$$
e=y-\hat{y} \text { where } \hat{\mathrm{y}}=X \beta, e^{T} e=[y-X \beta]^{T}[y-\hat{y}]=[y-X \beta]^{T}[y-X \beta]
$$

By applying partial derivative with respect to $\beta$, gives: $\beta=\left(X^{\mathrm{T}} \mathrm{X}\right)^{-1} \mathrm{X}^{\mathrm{T}} \mathrm{Y}$ and $\mathrm{t}$-test was used to test the individual parameter of the model.

\subsection{Model Adequacy Checking}

This model would be checked whether the major or standard assumptions of multiple linear regression model assumption are met. Linearity, homoscededicity, Autocorrelation, multicollinearity were tested.

Correlation analysis: Correlation analysis is used to measure the degree of correlation between variables. It also measures the degree of no association between any of variables. Correlation coefficient is a statistical measured that used to measure the relationship between the variables. The values of the correlation coefficient lie between -1 and 1 .

i. 1 indicates a strong positive relationship.

ii. -1 indicates a strong negative relationship.

iii. a result of zero indicates no relationship at all.

\section{Result}

The summary of descriptive statistics and result of inference statistics were interpreted and discussed below:

Table 1. Summary of Descriptive Statistics for Continuous Variables.

\begin{tabular}{llllll}
\hline Variable & N & Mean & Std Dev & Sum & Minimum \\
\hline Saved & 106 & 3486 & 2242 & 369547 & 1000 \\
Age & 106 & 29.41509 & 2.94349 & 3118 & 24.00000 \\
Salary & 106 & 10986 & 7435 & 1164528 & 8000 \\
Fam_Size & 106 & 2.17925 & 1.43293 & 231.0000 & 1.00000 \\
Consum & 106 & 3308 & 3843 & 350600 & 1200 \\
Rent & 106 & 966.50943 & 347.21488 & 102450 & 0 \\
Don & 106 & 322.68868 & 287.16278 & 34205 & 0 \\
Rec & 106 & 267.56604 & 177.29545 & 28362 & 0.00000 \\
Experience & 106 & 3.37028 & 1.88232 & 357.2500 & 0 \\
\hline
\end{tabular}

Table 1: revealed that the average values of monthly consumption of lecturers, monthly recreation of lecturers, monthly donation of lecturers, monthly salary of lecturers, monthly save of lecturers, Family size of lecturers, years of lecturers working in this area, Age of lecturers, monthly house rent of lecturers, are 3308, 267.56604, 322.68868, 10986, 3486,
2.17925, 3.37028, 29.41509 and 966.50943 respectively.

The range of variable contained in the minimum and maximum column level indicates that, the consumption, recreation, donation, house rent, salary, family size, age, working in this area and save of the instructors are 1200 to 35000,0 to 1000,0 to 1200,0 to 2000,8000 to 80000 , 
1.0000 to $10.0000,24$ to $47,0.25000$ to 11.00000 and 1000 to 25000 from respectively.

Table 2. The Summary of Descriptive Statistics for Categorical Variables.

\begin{tabular}{lllll}
\hline Variable & Category & Average saved money & Average & St. deviation \\
\hline \multirow{2}{*}{ sex } & Male & $92(86.79 \%)$ & 3497.25 & 2382.971 \\
& Female & $14(13.21 \%)$ & 3414.29 & 924.751 \\
Marital status & Single & $59(55.6 \%)$ & 3278.76 & 798.715 \\
& married & $47(44.4 \%)$ & 3746.81 & 3247.799 \\
\multirow{2}{*}{ Religion } & Orthodox & $53(50 \%)$ & 3248.58 & 776.463 \\
& Muslim & $15(14.15 \%)$ & 3325.33 & 819.060 \\
& protestant & $33(31.13 \%)$ & 3336.12 & 9794.488 \\
\hline
\end{tabular}

Table 2: displayed that it has seen that $86.79 \%$ of respondents are male and $13.21 \%$ of the respondents are female. In the above table $55.6 \%$ of the respondents are single, $44.4 \%$ of respondents are married and from the above table $50 \%$ of respondents are orthodox, $14.15 \%$ are Muslim, $31.13 \%$ are Protestants and $4.72 \%$ are others.

\section{Inferential Statistics}

It is the set of methods used to generalize from sample to population. By performing hypothesis testing determining relationship of variables and making prediction. It is drawing conclusion based on the obtained numerical analysis.

Table 3. Model Summary.

\begin{tabular}{llll}
\hline Model & R & R Square & Adjusted R square \\
\hline 1 & $.953^{\text {a }}$ & .908 & .897 \\
\hline
\end{tabular}

Table 3: showed that multiple coefficients of determination $\left(\mathrm{R}^{2}\right)$ show that about $90.8 \%$ of the proportion of variation in saving teacher (instructor) explained by all the predictors. On the other hand, $9.2 \%(100-90.8)$ identify as the elastic factors that is uncontrollable. Adjusted $\mathrm{R}$ Square indicates that $89.7 \%$ of variation in saving caused by other factors. $\mathrm{R}^{2}=$ 0.908 this implies that $90.8 \%$ of the amount of variation in the Lecturers money saving that is explained by the variation of predictors such as age of lecturers, sex of lecturers, family size of lecturers, religion of lecturers, Gross salary of lecturers, marital status of lecturers, Family size of lecturers, Donation of lecturers, Recreation of lecturers, house Rent of lecturers, and Experience.

Table 4. Over all Model Assessment Analysis.

\begin{tabular}{lllll}
\hline Source & DF & Sum of Squares & Mean Square & F Value \\
\hline Model & 8 & 478351161 & 59793895 & 116.94 \\
Error & 97 & 49597611 & 511316 & \\
Corrected Total & 105 & 527948772 & & \\
\hline
\end{tabular}

Table 4 showed that predictors: (Constant), Age of lecturers, donation per month, Family size of lecturers, family consumption of lecturers, and monthly income of lecturers. The $\mathrm{p}$ - value for all parameters is 0.00 which is less than the level of significance. So we reject Ho. We conclude that the regressor is jointly significance. Sum square regression shows there is a relationship between saving and predictors.

Table 5. Parameter Estimate of Multiple Linear Regressions by using Forward Selection Method.

\begin{tabular}{|c|c|c|c|c|}
\hline Parameter & Est (S.E) & $95 \% \mathrm{CI}$ & & P-Value \\
\hline Intercept & $-2434.21(965.5427)$ & -4326.64 & -541.778 & 0.0117 \\
\hline Age & $107.7312(34.3973)$ & 40.3137 & 175.1488 & 0.0017 \\
\hline Salary & $0.5223(0.0400)$ & 0.4439 & 0.6008 & $<.0001$ \\
\hline Family_Size & $-241.460(97.9105)$ & -433.361 & -49.5588 & 0.0137 \\
\hline Consumption & $-0.4805(0.0841)$ & -0.6453 & -0.3156 & $<.0001$ \\
\hline
\end{tabular}

From table 5 the fitted regression Model is

$\hat{Y}-2434.21+107.7312 X_{1}+0.5223 X_{2}-241.460 X_{3}-0.4805 X_{4}$

Where $\hat{Y}=$ Money saving, $X_{1}=$ Age, $X_{2}=$ salary, $X_{3}=$ F-size, and $X_{4}=$ consumption.

Interpretation of coefficients: is. $\beta_{0}=-2434.21$ the value of lecturers money saving when the predictor variables are zero. $\beta_{1}=107.7312$ Age of lecturer is the change in the lecturers money saving when the change (increased) by one unit taking other variables as a constant.

Age of lecturer is increased by one year, and then average money saving of lecturer is increased by 107.7312 . $\beta_{2}=0.5223$ is the change in the lecturers money saving. The salary of lecturers is increased by one taking all other variables as a constant, and then average money saving of lecturer is increased by $0.5223 . \beta_{3}=241.460$ Family size of lecturers is the change in the lecturers of average money saving when the change (decreased) by one unit taking other variable constant. Family size of lecturers increased by one 
unit the lecturer average money saving decreased by 241.460 . $\beta_{4}=-0.4805$. Family consumption of lecturer is the change in the money saving of lecturers when the change by one unit taking other variables as a constant. This implies that Family consumption of lecturers increased by one unit, then the money saving of lecturers decreased by 0.4805 .

Table 6. Test of Multi co linearity.

\begin{tabular}{lll}
\hline \multirow{2}{*}{ Model } & \multicolumn{2}{l}{ Co linearity Statistics } \\
\cline { 2 - 3 } & Tolerance & VIF \\
\hline (Constant) & & 0 \\
Age & .411 & 8.37712 \\
family consumption & .041 & 9.41328 \\
Experience & .603 & 1.97693 \\
Family Size & .214 & 1.03005 \\
Salary & .050 & 1.51775 \\
House Rent & .463 & 0 \\
Recreation & .868 & 2.39000 \\
Donation & .824 & 8.37712 \\
\hline
\end{tabular}

Table 6 revealed that the VIF as an indicator of multi-co linearity and the larger values of VIF, is the more collinear the variables. As the rule of thumb, if the VIF of a variable exceeds 10 , that variable is said to be highly collinear. That means VIF is greater than 10 is the presence of multi co linearity. Generally, VIF for all explanatory variables are less than 10 which indicated that there is no co-linearity between explanatory variables.

Test of Normality and Linearity

Normal P-P Plot of Regression Standardized Residual

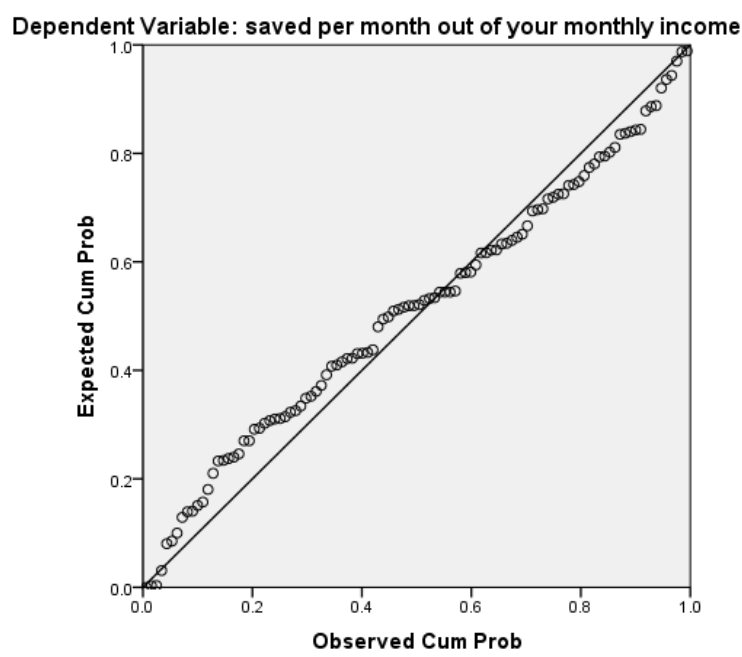

Figure 1. Test of linearity.

Linearity assumption: The observed values and predicted values of saving located in the line. As we can observe in the p-p plot graph indicates that all observations are lies approach to the line that means the relationship between dependant and independent variable should be linear. Due to this reason linearity assumption is satisfied.

Test of Normality

Test of Correlation analysis: Correlation analysis is used to measure the degree of correlation between variables. It also measures the degree of no association between any of variables. Correlation coefficient is a statistical measured that used to measure the relationship between the variables. The values of the correlation coefficient lie between -1 and 1 .

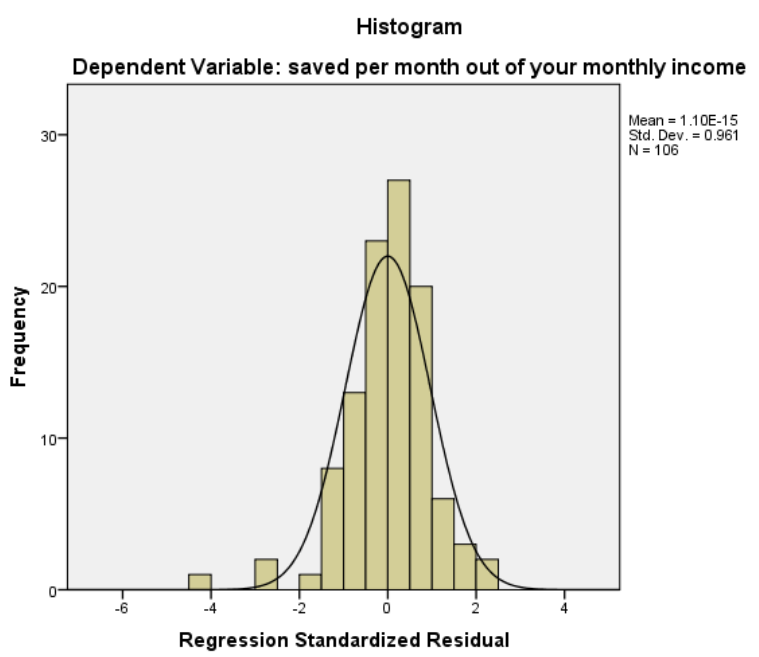

Figure 2. The graph seems like this and indicates the error term is normally distributed with mean zero and variance sigma squared. Thus, the assumption of normality is satisfied.

Table 7. Correlations Coefficient.

\begin{tabular}{llc}
\hline Variables & Correlation & P-value \\
\hline Family consumption and saving status of & 0.78 & $<.0001$ \\
lecturers & 0.89 & $<.0001$ \\
Gross salary and saving status of lecturers & 0.39 & 0.0137 \\
Family size and saving status of lecturers & 0.59 & 0.0017 \\
Age and saving status of lecturers & & \\
\hline
\end{tabular}

From the above table 7 , it has been seen that there is positive linear relationship between saving and consumption, Family size; Age and Salary of lecturers that means those four variables increase saving amount also increase. This analysis was confirmed by the above test, where the correlation is approximately strong and significant between Salary and saving, Age and saving, consumption and saving. But the correlation is approximately week and significant between family size and saving. The correlation between salary and saving is highest of others $(r=0.89)$

\section{Discussion}

Under the analysis, age, salary, and family Size are significantly influencing the average monthly saving among lecturers in Mizan-Tepi University, Tepi Campus, in case of Natural and Computational Science. This may be seen in different perspectives: Age is predominantly influencing the average saving money among lecturers and it perhaps the work habit or engaging in different investment, factories and machinery decreases as expenditure increseases when income remain constant is directly and indirectly related to the study under [7]. Family size is significantly influencing the average saving money among lecturers and it may be resulted from the size of households or the numbers of households dependent on only income and no additional income payment. This study consistently supported [5]. Salary associated with average money saving among lecturers and 
as it is known the income of respondents are quietly different since there was academic position difference even there was expatriate. Here, the expenditure also different even they have the same income. In fact, age, family size and income are correlated, and if there is constant income while there is no additional income, machinery, industry and investment, the average money saving among lecturers will be decreased. This study consistently supported $[5,6]$.

\section{Conclusions}

The main objectives of this study is to identify factors affecting the money saving of lecturers such as sex, age, donation, recreation, family size, religion of lecturers, Gross salary of lecturers, Family consumption, house rent, years of lecturers working in this area and marital status.

From multiple linear regression model Age, Family size, Family consumption, salary and donation are significantly affect the lecturers money saving. From the ANOVA table the regression value is less than $5 \%$ overall regression model is significance that the predictor variable (Age, Family size, Family consumption, donation and salary affect lecturers money saving.

Among the variables identified, age and salary of lecturers have positive effect on lecturer's money saving But Family size and Family consumption have negative effect on money saving of lecturers. From the study (recreation, Experience, sex, marital status, Donation and house rent) of the lecturers have no effect on lecturers money saving particularly based on this study

i. The association between the saving capacity of lecturers and salary of lecturers plays an important role on saving performance.

ii. Based on the finding of the study, it is conducted that saving of lecturers is increases if it has a positive relationship with income that means when the income increases the saving is also increases.

iii. There is a negative relationship between saving capacity of teachers with Family consumption of teacher's and Family size of the teachers that means when those Two factors increases the saving is decreases.

iv. As it has been indicated from the analysis data of inferential statistics contribution of a house rent, sex, Experience, recreation, Donation, Religion and marital status has no relationship with the saving capacity of lecturers and income and Age are the most important determinants of money saving.

\section{Recommendation}

i. The most objective (analysis part) of this research paper shall give various result and interpretation based on saving capacity of lecturers. From that point of view, I would like to recommend some point. First, as it has been shown from the analysis of inferential statistics, lecturers maximize its saving by increasing average monthly income and by decreasing Family consumption and Family size therefore lecturers have to use these factors wisely to increase the saving capacity.

ii. The stabilized use of these described factors leads to increase contribution for both country and individuals because increasing of saving leads to increase investment as well as country's growth so, every lecturers has to responsible to stabilized use of those factors.

iii. Also for a unit increase of inflation rate, the Government must increase the income of the teachers just by that amount and he have to supply goods and services by lowering the cost of it to solve these problems.

iv. Finally, I want to recommend that teachers saving capacity have dependency within these above variables, so a person who are concerned by this saving capacity he/she will be an able to improve these activity in different angles. Make it a habit to "save as" money regularly.

\section{Acknowledgements}

We would like to address and thanks our heartfelt gratitude to God and secondly we find no words to articulate our acknowledgements to Mizan Tepi University, College of Natural and Computational Science, Tepi Campus to do this study.

\section{References}

[1] Gohale, (2000). "Personal saving in developing Nation's further Evidence".

[2] E. Mark- Hanson. (1992) Educational Demonstration and Organization $5^{\text {th }}$ edition.

[3] Karim, (2010). Personal saving merit and money growth.

[4] Green Wald et al, (2001). The goal of promoting financial saving habit.

[5] World book Encyclopedia (E), Vilene Wudemelese and Tefera Tares (1998) Basic concepts of Education and curriculum: 3rd edition.

[6] Sherraden et al, (2007). The prances and benefits of asset accumulation for willingness to Chicago.

[7] Paula new and B. E Mark Hans on old (ed) (1989) Statistics for Business and Economics: $8^{\text {th }}$ edition.

[8] Friedman, Milton. 1972. "Comments on the Critics" Journal of Political Economy, September, October pg 913.

[9] Adam's, (1998). Mobilizing money saving through rural financial markets. Ohio state university; university of Chicago.

[10] Cochran (1997 Sampling Techniques: third edition.

[11] Montgomery, C. (2003). Introduction to linear regression analysis. 3rd Edition New York. 